\title{
nature
}

24 March 2005 Volume 434 Issue no 7032

\section{Joys of (top-notch) supervision}

The roles of mentors in research are seldom appreciated, let alone rewarded. All the more reason to celebrate the winners of the Nature/NESTA awards for creative mentoring in science.

$\mathrm{O}$ ne hears horror stories about labs all too often. Graduate students who are left to sink or swim. Highly competitive environments in which people don't talk to each other. Labs where graduate students are at the beck and call of an overbearing lab head who treats them like fodder for his or her own glory...

Paradoxically or not, such tales often emerge from outstanding labs. It seems that 'incorrect' management and rank exploitation are no barrier to a record of outstanding scientific achievement - by the person doing the exploiting, at least.

Less often heard are tales of outstandingly good management. Most important, surely, are ways in which some lab heads empower their students not only to achieve outstanding work in their years of formation, but also to continue in that vein independently. Better still if the students hand on such empowerment to the next generation.

So we set out to look for such outstanding mentors.

We did so in collaboration with NESTA, the UK National Endowment for Science, Technology and the Arts. NESTA sits between the UK research councils and the arts funding agencies in supporting projects that foster individual artistic, technological and scientific creativity (see www.nesta.org.uk). Its terms of reference required the awards to be restricted to Britain.

\section{Worthy winners}

We decided to award two prizes. One, for a lifetime achievement in creative mentoring in science, goes to Tom Kibble, professor of physics at Imperial College London.

Whether through direct supervision or close collaboration at an early stage in their careers, the five distinguished researchers who nominated Kibble clearly felt a very close bond with him. He himself acknowledges the leadership of two other figures, Abdus Salaam and Paul Matthews, and says he learnt from them "the importance of creating not just a one-to-one relationship with a student but a group of students and postdocs who supported each other".

As his five nominating protégés testified, Kibble always made himself available, at least once a week. Some students are lucky if they see their supervisor more than once a year.

The key skill that students need to acquire, says Kibble, is the ability to select appropriate problems. His approach was to suggest initial problems to think about and then to encourage graduate students to find their own problems in their second or third years. His own work has been in the theory of the very early Universe and the development and observable consequences of defects in the ground-state structure of the vacuum.

The judges of the competition (see www.nature.com/nature/ nestaawards/index.html) recognized some common characteristics of the shortlisted candidates. Many of these were well captured by one of Tom Kibble's nominators: "He has the knack of listening to others and giving his opinion so that one feels one's ideas are worthwhile. I have never heard of him being too busy to talk to someone. I have never heard him give the impression that someone's work was clearly wrong. Instead he would run it round and reformulate the idea so that it was something sensible to pursue." His protégés also appreciated the breadth and depth of his scientific insight.
Our other winner, of a mid-career award, is Innes Cuthill, professor of behavioural ecology at Bristol University, who designs innovative experiments to test questions about the selective forces that shape animal form and behaviour.

Again, protégés speak of an open door, and an ability to listen with a sharp mind and strike a balance between suggestions and leaving the student free to develop his or her own ideas - and also, an approach tailor-made for each student. As one of his nominators said: "He happens to be an incredibly original thinker and creative scientist who knows how to bring out these qualities in others. Mentoring isn't something Innes does in addition to being a scientist. It is totally integral to the way he does science."

"Innes understands that everybody works in their own idiosyncratic way," said another. "Throughout my career I have watched other colleagues being moulded to specific ways of working and thinking by their supervisors and lab leaders. But as far as I know, Innes has never done this with any of the countless undergraduate and postgraduate students who have passed through his door."

Mentors sometimes need imagination in finding the way to be supportive. When one $\mathrm{PhD}$ student asked for an assistant to help achieve a task, Cuthill said he would act as his research assistant: "Just tell me what to do." As Cuthill recalls: "He felt his supervisor had confidence, I was there on hand when he had doubts, and showed I wasn't expecting him to do anything I wasn't also doing myself. I have followed this model ever since."

\section{Top tips}

Nature and NESTA hoped that the competition might expose not only the characteristics of mentors but also techniques that others might adopt. In the end, the message seems to be that personality plays the dominant role. But we encouraged entrants to suggest general principles, and it seems appropriate to record Cuthill's:

- Never let a student think they have asked a silly question. Otherwise you risk stifling enthusiasm and killing self-confidence.

- Get involved in the research. Be their research assistant. It shows your enthusiasm for their work more effectively than (just) checking stats and draft manuscripts. And you can spot technical errors and improvements that might otherwise be missed.

- Give students time to reach their own conclusions: do not immediately jump in with the solution.

- Remember to emphasize the positive. Young researchers don't know that draft manuscripts often need heavy reworking and that even good papers get rejected.

- Emphasize that science isn't personal. When someone criticizes your work, they are not criticizing you.

- A supervisor must earn co-authorship by doing more than the normal role of a supervisor.

Nature is delighted to congratulate these winners and, inspired by these and others nominated for the awards, will be highlighting the role of mentors in future issues. We expect to organize more mentorship awards, in Britain and elsewhere. In doing so, we seek to celebrate not only the best of science's laboratory culture, but also outstanding examples of its humanity. 